\title{
Habermas sobre a comunicação sistematicamente distorcida
}

\author{
Habermas on systematically distorted communication
}

\author{
Aylton Barbieri Durão[ ${ }^{[a]}$, Adja Balbino de Amorim Barbieri Durão ${ }^{[b]}$
}

[a] Doutorado em Filosofia pela Universidad de Valladolid, Espanha, professor adjunto da Universidade Federal de Santa Catarina (UFSC), Florianópolis, SC - Brasil, e-mail: barbieri@cfh.ufsc.br

[b] Doutorado em Linguística pela Universidad de Valladolid, Espanha, docente do Departamento de Letras da Universidade Federal de Santa Catarina (UFSC), Florianópolis, SC - Brasil, e-mail: adja@cce.ufsc.br

\section{Resumo}

Habermas desenvolveu a teoria da ação comunicativa mostrando como os problemas de comunicação entre os falantes podem ser resolvidos a partir da própria autorreferencialidade inerente à linguagem ordinária ou, em casos mais graves, mediante os discursos racionais. Contudo, ele mostrou também que existem formas de comunicação sistematicamente distorcidas como a neurose e a ideologia, nas quais, ao contrário de Wittgenstein, que considerava não existir uma linguagem privada. Tratava-se somente de um mal entendimento sobre o correto funcionamento de nossa linguagem, pois são formas reais da linguagem privada porque a reconstrução linguística da Psicanálise demonstrou que o neurótico, diante de uma situação insustentável da primeira infância, substitui o símbolo reprimido por um símbolo insuspeito que passa a ocupar o seu lugar. Origina o comportamento repetitivo do enfermo, mas que pode ser recordado de maneira constante, 
o que desmente também o primado que Gadamer atribuiu à hermenêutica. A comunicação sistematicamente distorcida não pode ser superada simplesmente pelo adestramento da habilidade de interpretação a partir do contexto, mas requer a passagem para discursos clínicos em que o paciente deve fazer a experiência da autorreflexão.

Palavras-chave: Hermenêutica. Psicanálise. Neurose. Ideologia. Patologia.

\section{Abstract}

Habermas developed the theory of communicative action, which shows how the problems of communication between speakers may be solved based on the self-referentiality inherent to ordinary language or, in more severe cases, based on rational discourses. However, he also showed that there are forms of communication systematically distorted, such as neurosis and ideology, in which, contrary to Wittgenstein, who considered the non-existence of a private language, since it was a misunderstanding on the correct functioning of our language. They are real forms of private language because the linguistic reconstruction of psychoanalysis showed that the neurotic person, in face of an unsustainable situation from his/ her infancy, replaces the repressed symbol by a non-suspect symbol which comes to occupy its place, originating a repetitive behavior on the part of the sick person, but which may be recalled in a constant way, what also contradicts the primacy that Gadamer attributed to hermeneutics, since the systematically distorted communication cannot be overcome simply by the taming of the ability to interpret based on context, but requires the passage to clinical discourses in which the patient must undergo the experience of self-reflection.

Keywords: Hermeneutics. Psychoanalysis. Neurosis. Ideology. Pathology.

Habermas aborda o problema da comunicação sistematicamente distorcida em quatro publicações: os capítulos 10 e 11 de Conhecimento e interesse, em 1968 (HABERMAS, 1994); um artigo publicado em inglês intitulado "A comunicação sistematicamente distorcida" (HABERMAS, 1970) e outro denominado "A pretensão de universalidade da hermenêutica" (HABERMAS, 1985), ambos de 1970; e, por último, o artigo "Considerações sobre patologias da comunicação", escrito em 1974 e incorporado aos Complementos e estudos prévios à teoria da ação comunicativa (HABERMAS, 1995a). 
Inicialmente, Habermas observou, em Conhecimento e interesse, como Kant, Hegel e Marx, ao mesmo tempo em que estiveram em condições de desenvolver a teoria do conhecimento, cometeram vários equívocos que possibilitaram a gênese do Positivismo. Assim como explicou, posteriormente, que, no interior do próprio Positivismo se desenvolveu uma metodologia capaz de refletir sobre as condições de possibilidade das ciências da natureza, a partir de Pierce, e das ciências do espírito, a partir de Dilthey, os quais, tomando por base a práxis vital, desvelaram a vinculação entre conhecimento e interesse, obliterada pelo cientificismo. Enquanto o Positivismo pretendia demonstrar o caráter neutro das ciências com relação aos interesses, Habermas observou como o conhecimento produzido pela espécie humana explicita o interesse que ela possui por sua própria emancipação. Por isso, as ciências da natureza explicam como a humanidade pode se libertar das cadeias impostas pela natureza mediante o trabalho, assim como as ciências do espírito expressam o interesse prático por meio do qual a interação pode se reproduzir em condições sociais de não dominação. Contudo, e ao contrário das pretensões da primeira geração da Escola de Frankfurt, que pensava na possibilidade de uma identidade do homem com a natureza e com relação ao próprio homem, a reconstrução do conceito de trabalho, por um lado, como uma forma da ação instrumental, revela precisamente como os instrumentos transcendentais de apreensão do conhecimento dos objetos ocasionam uma distinção no modo como eles são em-si-mesmos e no modo como se mostram para-nós. Enquanto, por outro lado, Dilthey pensou que essa distinção entre a coisa-em-si e a coisa-para-nós só poderia ocorrer no contexto das ciências da natureza, mas não no das ciências do espírito, já que existe uma profunda diferença entre a metodologia explicativa das ciências da natureza, cujos objetos existem anteriormente e independentemente dos sujeitos do conhecimento, os quais podem simplesmente ser transformados pelo trabalho, e a metodologia hermenêutica das ciências do espírito, a qual permite a compreensão do objeto em-si-mesmo, uma vez que ele é produzido pela práxis vital da própria humanidade.

Habermas reconhece que a hermenêutica realizou um importante trabalho na investigação sobre as condições de produção do 
conhecimento. A teoria do conhecimento surgiu, inicialmente, no âmbito do idealismo alemão que, não obstante, atribuiu a atividade cognitiva a um sujeito compreendido de forma abstrata e monológica, abrindo o flanco para que o Positivismo, ao criticar o subjetivismo idealista, pudesse introduzir um objetivismo na metodologia das ciências, o que acabou por resultar na repressão e no esquecimento de toda a teoria do conhecimento. A hermenêutica, por outro lado, desmantelou a cortina de objetivismo lançada pelo Positivismo, permitindo-lhe recordar o reprimido e o esquecido, na medida em que compreendeu o conhecimento como um produto dos seres humanos em sua práxis vital sobre os objetos, a qual, como se constitui mediante o trabalho e a interação, só pode ser dialógica, portanto, superando também as consequências abstratas e monológicas do idealismo (HABERMAS, 1985, p. 337).

Habermas argumenta que a hermenêutica não percebeu que, na interação como modo da ação comunicativa, podem surgir formas de comunicação sistematicamente distorcidas que obliteram o conhecimento sobre objetos culturais reprimidos e esquecidos. Por isso, o interesse emancipatório da espécie, em lugar de pretender constituir um novo domínio de objetos, aspira, na verdade, dissolver as falsas objetividades geradas pela comunicação sistematicamente distorcida, originando um novo tipo de ciência, definidas como ciências críticas, tais como a Psicanálise ou a crítica da ideologia, as quais pensam seus objetos terapeuticamente como patologias que devem ser tratadas mediante a experiência da reflexão.

Em "A pretensão de universalidade da hermenêutica", Habermas insiste em sua crítica sobre a cegueira da metodologia hermenêutica acerca da comunicação sistematicamente distorcida, mas, se em Conhecimento e interesse o alvo era o trabalho de Dilthey, agora o propósito de Habermas é desenvolver uma polêmica com Gadamer ${ }^{1}$.

\footnotetext{
1 No Brasil, 0 debate entre Habermas e Gadamer foi recolhido no livro organizado por Álvaro Valls: VALLS, A. (Org.). Jürgen Habermas. dialética e hermenêutica: para uma crítica da hermenêutica de Gadamer. 4. ed. Porto Alegre: L\&PM, 1987, que inclui um comentário de Ernildo Stein. Esse artigo pretende unicamente expor o ponto de vista de Habermas sobre a comunicação sistematicamente distorcida, mas, para uma apreciação das respostas de Gadamer, podem ser consultadas as obras de Ernildo Stein incluídas nas referências.
} 
O problema da hermenêutica se inicia porque Gadamer, após um exame correto sobre a relação entre a linguagem formal e a linguagem ordinária, sobrecarrega esta última com uma pretensão de universalidade. Enquanto as linguagens formais não podem comentar a si mesmas como linguagens objeto, como o demonstra a teoria dos tipos proposta por Russell e, por isso, uma linguagem formal só pode ser explicada mediante outra linguagem formal, o que gera uma série hierarquizada de linguagens formais, segundo a qual cada membro da série funciona como metalinguagem da anterior, a linguagem ordinária, por outro lado, dispõe da capacidade de fazer a reflexão sobre seu próprio funcionamento. A autorreferência da linguagem ordinária permite que ela possa refletir sobre si mesma, sem a necessidade de utilizar uma metalinguagem. Por conseguinte, na hierarquia das linguagens formais, uma como metalinguagem das anteriores, a linguagem ordinária aparece como a última da série, pois não depende de outra metalinguagem quando os problemas de comunicação, que necessitam de esclarecimento, surgem em seu interior. Esta autorreferencialidade causou em Gadamer o pensamento de que não há nenhuma estrutura anterior à linguagem ordinária e que tudo pode ser resolvido mediante a hermenêutica da linguagem ordinária, como última metalinguagem (HABERMAS, 1985, p. 338).

Habermas compartilha a tese de que a linguagem ordinária é a última metalinguagem exatamente por causa de sua autorreferencialidade, mas isso não o leva a acreditar na sua pretensão de universalidade, como propõe Gadamer. Isso é assim, em primeiro lugar, porque existem elementos de natureza pré-linguística que antecedem à linguagem. Habermas assinala três desses elementos: os esquemas categoriais da inteligência operativa expostos por Piaget, as estruturas do inconsciente desveladas por Freud e as regras gerativas da competência linguística enunciadas por Chomsky.

Piaget mostra que o indivíduo, em seu desenvolvimento cognitivo, antes de aprender a linguagem, apresenta uma inteligência operativa, porque as categorias de substância, causalidade, espaço e tempo já estão constituídas antes que a criança possa incorporá-las na linguagem e, por meio delas, ela pode agir operativamente sobre o mundo. 
Os estudos de Piaget revelam que a linguagem "monta" sobre esses conceitos pré-linguísticos, incorporando-os à fala cognitiva. Do mesmo modo, Freud revela um conjunto de significantes anteriores à consciência e à linguagem, que se deixam entrever ocasionalmente por seu aparecimento repentino no mundo público, especialmente quando diminui a vigilância do ego, por exemplo, nos sonhos, embora também nas patologias, ou, ainda, na produção criativa do indivíduo. Por fim, Chomsky reconstrói racionalmente as regras universais da linguagem ordinária, demonstrando que estas podem ser descritas segundo os elementos estruturais da teoria gerativista.

Para Habermas, contudo, como esses elementos pré-linguísticos estão integrados à linguagem ordinária e, portanto, o falante somente pode alcançá-los por meio da linguagem ordinária, isso não implica a renúncia ao primado da linguagem ordinária como última metalinguagem. Longe de desmentir, comprovam precisamente a sua autorreferencialidade. Por isso, a hermenêutica pode desenvolver a capacidade natural que todo falante possui de compreender o sentido linguisticamente comunicável, bem como de convencer e persuadir os demais em questões práticas que não podem ser resolvidas por demonstrações analiticamente rigorosas. A capacidade de compreensão permite lançar mão da autorreferencialidade da linguagem ordinária para resolver possíveis incompreensões recíprocas que podem ocorrer no caso da leitura de textos de épocas distantes no tempo ou procedentes de diferentes comunidades culturais, entre outras possibilidades. As ininteligibilidades provocadas pela distância cultural, temporal ou social estão dentro dos limites da comunicação habitual e podem ser resolvidas hermeneuticamente pelos participantes (HABERMAS, 1985, p. 343).

O que compromete a pretensão de universalidade da hermenêutica é a comunicação sistematicamente distorcida, na qual tudo ocorre de maneira diferente, porque os falantes em questão, por mais que desenvolvam uma competência natural para compreender as manifestações vitais, não podem se tornar conscientes das patologias da linguagem. O que caracteriza uma patologia, seja provocada por uma neurose ou uma ideologia, é sua peculiar falta de coerência para um indivíduo ou para a sociedade como todo. Essa incompreensão é de tal ordem 
que os envolvidos não são sequer capazes de perceber que algo vai mal na comunicação. Os neuróticos não podem usar sua competência natural para o autoesclarecimento de sintomas patológicos, do mesmo modo que uma sociedade submetida a uma ideologia não utiliza a sua capacidade de compreensão hermenêutica, pelo simples fato de nem sequer serem capazes de perceber a patologia a que estão submetidas, como patologias. O traço específico da ininteligibilidade é que não se percebe a ininteligibilidade como ininteligibilidade. A pseudocomunicação se baseia em uma aparência de consenso ou de acordo que não se observa como falsa. Somente se podem perceber os mal-entendidos comunicativos por meio da participação, mas, justamente por isso, o participante não consegue perceber os mal-entendidos, quando estes se devem a comunicações sistematicamente distorcidas (HABERMAS, 1985, p. 343-344).

Habermas não trata especificamente da ideologia em nenhuma das obras mencionadas, embora analise o caso da neurose detalhadamente, porque o considera o exemplo de patologia melhor estudado em que se revelam os limites da metodologia hermenêutica. As enfermidades mentais são casos nos quais é evidente que os afetados não podem se entender simplesmente a partir da sua capacidade hermenêutica, porque os enfermos resistem a trazer à consciência a própria enfermidade, como comprovou Freud no tratamento de neuróticos. Quanto mais o terapeuta se aproxima das causas da patologia, mais o paciente resiste, tentando se refugiar em mecanismos de defesa. Freud descobriu que não era suficiente que o terapeuta conhecesse a causa da enfermidade e que se limitasse a expô-la ao paciente, pois as melhoras advindas da revelação não duravam e o enfermo voltava ao consultório. Era necessário que o enfermo participasse de seu próprio processo de cura, trazendo a origem da enfermidade gradualmente à consciência, na medida em que superava seus próprios mecanismos de defesa e resistência. Por meio da metodologia reflexiva, o terapeuta desempenha o papel de auxiliar na superação das obliterações conscientes e orienta a autorreflexão do paciente a partir de pressupostos teóricos que definem o que é "normalidade" e patologia. Freud aplicou a mesma 
explicação, posteriormente, à civilização ocidental em suas obras sobre a cultura (HABERMAS, 1985, p. 344).

Habermas aproveitou as contribuições freudianas para discutir a metodologia da ciência em Conhecimento e interesse. O cientificismo obliterou o conhecimento das condições de produção do conhecimento, pondo um falso objetivismo baseado na eficiência dos meios técnicos e experimentais em lugar do sujeito cognitivo, quer dizer, a espécie que se reproduz a partir do trabalho e da interação, não somente materialmente, mas também mediante o conhecimento. Para superar as repressões do Positivismo não é suficiente que o epistemólogo revele as falsas objetividades reinantes, pois a ciência, a comunidade de pesquisadores e a sociedade em geral, devem participar do processo de superação da falsa aparência de verdade do cientificismo, por isso, Habermas se empenha em descobrir como no seio do próprio Positivismo, com Pierce, Dilthey e o próprio Freud (que acabou cedendo demasiadamente à fisiologia), a ciência começou a introduzir uma metodologia reflexiva.

Habermas concorda com a hermenêutica no que se refere à ideia de que os mal-entendidos só podem ser esclarecidos na comunicação a partir da atitude de participante envolvido e jamais como resultado de uma atitude objetivista de terceira pessoa do observador neutro. Contudo, discorda da hermenêutica em que a simples capacidade natural de compreensão dos falantes, por mais treinada ou especializada, possa superar as resistências que gera a falsa aparência de entendimento provocada pela comunicação sistematicamente distorcida. Apenas com uma metodologia reflexiva, na qual os próprios envolvidos possam gradualmente trazer à consciência as falsas objetivações e resgatar o entendimento do que foi reprimido, pode ser eficaz, mas, para isso, a reflexão deve dispor de um conjunto de hipóteses teóricas acerca do que vale como "correto". Portanto, a reflexão se distingue da hermenêutica, porque, enquanto esta se dirige a fenômenos que podem, em princípio, ser compreendidos com os recursos do adestramento da habilidade natural dos falantes a partir do primado interpretativo do contexto e das tradições, somente a reflexão trata de casos em que os mecanismos ocultos da compreensão não podem ser trazidos espontaneamente à luz, como ocorre com a neurose, por exemplo, pois se 
dirige a situações do tipo consciente/inconsciente, em que se devem ultrapassar as resistências para o esclarecimento das incompreensões.

Três critérios servem para exemplificar a ininteligibilidade da comunicação distorcida pela neurose:

1) o emprego dos símbolos linguísticos se desvia das regras da comunicação pública, o que pode afetar parcial ou totalmente a semântica e, inclusive, a sintaxe;

2) o comportamento passa a ser governado por ações rígidas e repetidas, o que faz com que o enfermo perca a capacidade de modificar suas ações em função do contexto, porque sempre se comporta de modo estereotipado diante de determinados estímulos;

3) por fim, é rompida a congruência entre símbolos linguísticos, comportamento e manifestações vitais (HABERMAS, 1985, p. 345).

Se, na ação comunicativa normal, a linguagem dispõe de uma peculiar independência do contexto, razão pela qual os falantes podem se expressar sobre qualquer conteúdo proposicional a partir de atitudes performativas muito variadas (como são as pretensões de verdade, sinceridade ou retidão dos enunciados) ao contrário, submetido a uma patologia, o usuário excomunga a linguagem do uso público, tornando-a privada e, consequentemente gera diferentes camadas de linguagem que se tornam discrepantes entre si.

Pode-se perceber, portanto, que, além da indubitável influência da Psicanálise de Freud sobre a teoria da comunicação, sistematicamente distorcida de Habermas, outra referência significativa provém das investigações de Wittgenstein acerca dos jogos de linguagem. Wittgenstein, em sua análise sobre a linguagem privada, pretende demonstrar o equívoco da interpretação do mentalista segundo a qual o significado da linguagem se define pela elucidação ostensiva privada em que o sujeito recorda um estado interno da consciência quando se refere a um símbolo. No modo de funcionamento normal da linguagem, descrito por Wittgenstein, os participantes de um jogo de linguagem, no qual linguagem e ação se entrelaçam, usam regras cuja definição é pública. Inclusive a manifestação de estados internos da consciência, 
como ter uma dor, por exemplo, forma parte de um jogo de linguagem que permite aos demais reconhecer a diferença entre o comportamento de alguém que sente dor e outro que não sente dor. Como as regras precisam efetivamente ser seguidas (regras que não são seguidas não são regras), a dúvida sobre a gramática da linguagem só pode ser resolvida mediante a investigação acerca do uso que os falantes realizam no jogo de linguagem, mas um uso privado das regras da linguagem consiste em definir a gramática da linguagem apelando para a lembrança de algum estado interno da consciência do sujeito isolado. Por isso, é impossível haver uma definição privada do símbolo porque, como somente o usuário poderia recordar o estado interno da consciência que crê que corresponde ao significado de um símbolo, não haveria nenhum critério para determinar se ele recorda exatamente o mesmo estado interno sempre que se refere ao símbolo. Portanto, qualquer estado interno da consciência que ele recordar como significado que atribui ao símbolo seria uma definição do significado do símbolo. Para Wittgenstein, o argumento da linguagem privada defendido pelo mentalista exige uma definição privada do significado dos símbolos, que implica um círculo semântico insuperável, porém, no funcionamento normal da linguagem, somente se pode recordar um estado interno da consciência quando se sabe o significado do símbolo a que se refere mediante a gramática que ele tem no jogo de linguagem; caso contrário, o próprio sujeito não poderia saber que estado interno de consciência teria que procurar (WITTGENSTEIN, 1989, p. 361-362).

Se o argumento de Wittgenstein contra a linguagem privada se dirige a uma falsa descrição feita pelo mentalista como modelo de funcionamento da linguagem, que ocorre quando se filosofa e, por conseguinte, quando a linguagem entra de férias, que pode ser desmentido pela investigação acerca do uso correto da gramática dos jogos de linguagem, Habermas, ao contrário de Wittgenstein, considera que a linguagem privada realmente ocorre na linguagem ordinária como uma patologia que afeta o modo de funcionamento "normal" da linguagem, embora na forma da neurose e da ideologia.

As patologias ocorrem porque uma parte da comunicação foi reprimida pelos próprios falantes e, para ocultar a ausência do símbolo, 
o falante usa, em seu lugar, outro símbolo insuspeito. Esse mecanismo não obedece mais às regras da linguagem pública, pois o falante usa o símbolo com um significado totalmente diferente do que lhe é atribuído na fala normal, conferindo-lhe um significado privado, que nem os outros falantes, nem sequer o próprio usuário compreende, uma vez que o símbolo insuspeito ocupa o lugar de um fenômeno que não pode ser lembrado. O mecanismo da repressão mostra como é possível haver uma linguagem privada, mas como patologia, e jamais como fala normal, porque explica como símbolos podem adquirir um significado constante e, contudo, inacessível aos seus próprios usuários.

Wittgenstein tem razão quando critica a definição do mentalista sobre o funcionamento da linguagem ao argumentar que o falante não teria como recordar o estado interno da consciência que atribui como significado de um símbolo definido privadamente e, então, qualquer símbolo que possa recordar valeria como significado para o símbolo. No comportamento neurótico, há uma espécie de mecanismo inconsciente de "lembrança", pois, sempre que as situações cotidianas ameaçam desnudar o trauma em questão, o sintoma ocupa o seu lugar, o que provoca o comportamento repetitivo do enfermo que age compulsivamente, sempre do mesmo modo, como reação aos problemas que se apresentam na comunicação ordinária. A compulsão repetitiva é uma prova de que os símbolos podem ter um significado privado, embora ele seja indisponível para o próprio falante.

Para explicar a linguagem privada, no caso da neurose, Habermas aproveita a interpretação linguística da Psicanálise que fez Alfred Lorenzer (HABERMAS, 1985, p. 345). Segundo Lorenzer, pode-se compreender o trabalho da análise psíquica por meio de uma representação cênica. O enfermo, em situações cotidianas, age de acordo com os sintomas da neurose; o analista tem que decifrar a cena sintomática e tentar, durante a consulta, gerar as condições responsáveis pelo trauma. A cena de transferência, elaborada pelo analista durante a consulta, reproduz a cena sintomática, pois se aceita o pressuposto de que o paciente se comporta do mesmo modo estereotipado que em situações cotidianas em função da repetição compulsiva de seu comportamento. O analista é empurrado pelo paciente, na cena de transferência, para 
o papel de pessoa de referência e pode perceber as origens da enfermidade, que se encontram em uma situação da primeira infância. A criança, confrontada com uma situação de conflito insuportável, se defende dele, eliminando a cena original causadora do trauma de sua consciência. A experiência traumática é excluída da comunicação pública e, tanto a própria cena como a pessoa de referência envolvida, são dessimbolizadas. Em lugar da cena original reprimida, a criança coloca um símbolo insuspeito que não lhe permite recordar, nem possibilita aos demais qualquer associação com a cena suprimida. Esse símbolo não pode ser usado como um símbolo da linguagem pública, pois obedece às regras da representação patológica, passando a ter um significado que ninguém compreende, inclusive o próprio usuário. Como o símbolo não tem relação com as regras públicas da linguagem, torna-se um sintoma repetido sempre que o enfermo se sentir ameaçado por situações vivenciais que lhe obrigariam a desvelar o trauma, daí a compulsão repetitiva da neurose, a dependência contextual do sintoma e o seu significado privado. Na vida ordinária do enfermo, a cena original dá lugar à cena sintomática. $\mathrm{O}$ analista deve, em primeiro lugar, repetir o jogo de representação do paciente na cena de transferência realizada na consulta. Na cena de transferência, ele assume o papel de pessoa de referência pelo enfermo e pode perceber o nexo entre a cena original e a cena sintomática, reconstruir um léxico entre as duas cenas e possibilitar o ato de autorreflexão do paciente. Pela reflexão, os significados privados são esclarecidos e os símbolos divididos são integrados à consciência. Nisto consiste a "ressimbolização" dos elementos reprimidos.

Esse processo, evidentemente, não pode ser realizado a partir da compreensão hermenêutica cotidiana, porque a representação linguística da clínica exige o uso de um conjunto de hipóteses teóricas com um método experimental específico (diferente com relação às ciências naturais e do espírito), o qual não pode ser empregado por um falante comum no uso ordinário da linguagem, por mais adestrado que seja na habilidade da compreensão. O esclarecimento da neurose, como das comunicações sistematicamente distorcidas em geral, exige o desenvolvimento de uma ciência de tipo especial, a qual Habermas denominou ciências críticas (como a Psicanálise e a crítica da ideologia). 
Do ponto de vista metodológico, as ciências críticas se distinguem da hermenêutica, por um lado, porque o desenvolvimento do método de livre associação de ideias, de Freud, mostra que as condições na clínica não são as da comunicação cotidiana, pois o paciente deve ser liberado das pressões da vida e participar de uma comunicação baseada no diálogo terapeuta-paciente. Esse diálogo, por outro lado, também não cumpre as condições idealizadas dos discursos teórico e prático que pretendem chegar a um consenso na ciência ou na ética, respectivamente, em que todos os envolvidos se orientam pela busca cooperativa da verdade ou do entendimento recíproco, todos os afetados têm que poder dar seu assentimento à norma e, onde só vale a força do melhor argumento, pois, na clínica, existe uma inevitável desigualdade de papéis, já que o terapeuta deve orientar o paciente rumo à autorreflexão. Quer dizer, o diálogo psicanalítico está a meio caminho entre a situação de fala real, na qual vigoram as condições sociais, e a situação ideal de fala, como ideia reguladora em que se cumpririam as fortes idealizações assinaladas pela teoria do discurso, pois, por um lado, o diálogo psicanalítico pretende dissolver falsas concepções e orientar a reflexão, partindo de uma desigualdade inequívoca de papéis que serão desempenhados pelos participantes; por outro lado, se dirige a um fragmento incompreensível de significados muito específico: as relações da infância perturbadas por conflitos. Essas descrições metodológicas configuram condições quase experimentais que se distinguem claramente tanto da situação de compreensão hermenêutica como dos discursos racionais das ciências em geral (HABERMAS, 1995b, p. 182-183).

Enquanto a compreensão hermenêutica deve aproveitar e desenvolver a capacidade natural dos falantes, o diálogo psicanalítico necessita de um conjunto de pressupostos teóricos que ultrapassa as condições de comunicação cotidiana, mesmo adestradas como uma habilidade. Habermas distingue esses pressupostos teóricos segundo três perspectivas: o psicanalista (1) deve dispor de uma compreensão da comunicação normal; (2) tem que explicar a comunicação sistematicamente distorcida como uma confusão entre duas fases da organização linguística geneticamente separadas; (3) e, por fim, deve descrever a 
deformação a partir de uma teoria dos desvios na estrutura da formação da personalidade. Esse conjunto de pressupostos teóricos do terapeuta demonstra também porque o diálogo psicanalítico não pode ser do mesmo tipo que os discursos teóricos ou práticos, pois revelam a peculiar desigualdade de papéis entre o terapeuta, que orienta a autorreflexão, baseando-se neles, e o paciente, que não é integralmente capaz de razões e deve realizar o processo de autorreflexão (HABERMAS, 1985, p. 348).

Na tarefa de orientar a autorreflexão sob as condições controladas da clínica, o terapeuta necessita estabelecer um critério de comparação entre o comportamento linguístico normal e o distorcido:

(1) os três planos da comunicação, a linguagem simbólica, as ações e as expressões corporais devem ser congruentes entre si, a ponto de se complementarem metacomunicativamente, ou seja, pode-se usar um modo de comunicação para auxiliar o outro com o fim de reforçar uma expressão, abreviá-la e mudar-lhe o sentido até chegar ao ponto de contradizê-la. Um gesto pode ser compreendido, por exemplo, como uma comunicação que comenta ou explica a linguagem verbal; trata-se de uma metacomunicação, porque comunica algo sobre a comunicação. $\mathrm{O}$ mesmo pode ocorrer em sentido contrário, e o comportamento extraverbal pode ser transformado em metacomunicativamente verbal, como sucede, por exemplo, quando um falante não entende uma ação ou uma manifestação vivencial e necessita que o outro as explique verbalmente. Naturalmente, a congruência é vedada ao enfermo mental que nem sempre é capaz de se expressar livremente sobre seu comportamento. A repressão é uma comprovação de que parte de seu comportamento não pode ser verbalizado (HABERMAS, 1985, p. 348);

(2) na comunicação normal, os falantes usam uma linguagem pública, cujas regras são intersubjetivamente compartilhadas. A comunicação extraverbal também segue um conjunto de regras determinadas pela cultura e pela sociedade, que são compreendidas rotineiramente por seus membros. Com a patologia, a publicidade das regras gramaticais ou extraverbais é rompida, pois uma parte do comportamento (linguístico ou não) torna-se inacessível à comunicação (HABERMAS, 1985, p. 348); 
(3) na fala normal, pode-se distinguir entre ser e aparência, porque ela está estruturada de tal modo que é possível perceber a função de determinados elementos da linguagem. Pode-se separar o sujeito próprio do objeto, o mundo privado do público, assim como o significado e o referente de um símbolo. $\mathrm{O}$ sujeito somente pode distinguir ser e aparência porque a linguagem adquire uma realidade diferenciada em relação aos objetos da experiência e das vivências privadas. Uma característica da enfermidade mental é, sem dúvida, abalar a diferenciação entre ser e aparência que, em casos extremos, pode gerar uma confusão entre o sujeito próprio e o objeto, ou entre a realidade objetiva e a experiência privada (HABERMAS, 1985, p. 348);

(4) na comunicação normal, o processo de individuação se divide, por um lado, na identificação dos objetos pela linguagem formal e, por outro, na individualização dos sujeitos mediante a linguagem ordinária. Na lógica das classes, descrita inicialmente por B. Russell, o particular deve ser definido como elemento de uma classe e uma classe como reunião de particulares; as classes, por sua vez, podem ser reunidas em classes de classes, segundo uma lógica da inclusão de classes. A individualização dos sujeitos, por outro lado, se forma e conserva a partir da intersubjetividade da linguagem ordinária mediante uma lógica dos pronomes pessoais, que segue uma dialética do reconhecimento. Na peculiar dialética dos pronomes pessoais, o indivíduo surge por um processo de reconhecimento de si mesmo que se vincula ao reconhecimento do outro e do grupo. Um "eu" somente se reconhece a si mesmo porque realiza a experiência de ser absolutamente diferente de outro "eu", o "tu", e, por meio da percepção desta alteridade fundamental, pode reconhecer, por sua vez, a sua identidade com este outro, na medida em que, juntos, compõem um grupo, o "nós". O "nós" realiza a mesma experiência do "eu", pois seu autorreconhecimento exige o reconhecimento de outros "eus", que são a negação de si mesmo, uma vez que aparece como os outros do "nós", "eles", e novamente pode, por este caminho que o "nós" reforça a sua particularidade, reconhecer também a sua identidade com o "eles". A lógica dos pronomes pessoais, ao mesmo tempo em que possibilita a constituição do "eu", do "tu", do "nós" e do "eles", por meio da negação e da afirmação, da alteridade 
e do reconhecimento, assenta a base de uma intersubjetividade da comunicação que é condição para a fala normal. Contudo, na linguagem patológica, a confusão entre ser e aparência prejudica tanto o reconhecimento recíproco e a intersubjetividade como o uso analítico da linguagem. Tanto a dialética dos pronomes pessoais como a lógica das classes e, em consequência, a formação de indivíduos (sujeitos ou objetos) e seus agrupamentos (grupos sociais ou classes de objetos) seguem um processo genético desviado e híbrido (HABERMAS, 1985, p. 349);

(5) Por fim, o uso diferenciado da linguagem em relação aos objetos da experiência ou aos sujeitos falantes implica uma distinção na esquematização das categorias. Piaget demonstrou que se podem recuperar, em termos de psicologia cognitiva, as categorias do entendimento de Kant como conceitos fundamentais que se desenvolvem ontogeneticamente. Pelo menos as categorias de substância, causalidade, espaço e tempo se revelam como constituidoras do conhecimento possível. Essas categorias devem ser aplicadas distintamente a domínios de objetos igualmente diferenciados ou, em termos kantianos, retomados por Habermas, a aplicação de categorias a um domínio de objetos se chama esquematismo. A esquematização das categorias aos corpos em movimentos tem que ser diferente quando se trata de sujeitos que falam, pois a categoria de substância se distingue obviamente quando é compreendida como a individuação sob a lógica das classes ou sob a dialética dos pronomes pessoais, a causalidade tanto pode ser a causa de fenômenos mensuráveis quanto dos motivos da vontade, bem como espaço e tempo se diferenciam em grandezas naturais ou circunstâncias históricas. $\mathrm{O}$ mesmo engano entre ser e aparência, que já havia abalado a distinção entre a lógica das classes e a dialética de pronomes pessoais que originam a individuação, prejudica também a esquematização dessas categorias de acordo o domínio de objetos, em casos patológicos (HABERMAS, 1985, p. 351).

Além de um conhecimento da fala normal em contraste com a patológica, é necessária a diferenciação teórica entre duas etapas geneticamente consecutivas da comunicação humana (HABERMAS, 1985, p. 351).

A fase mais antiga da comunicação, cujos elementos pré-linguísticos Habermas denomina como paleossímbolos, não pode ser 
alcançada diretamente, ou encontrada explicitamente. As características da comunicação primitiva impedem seu aparecimento como um sistema linguístico próprio, uma vez que não dispõe das propriedades inerentes à linguagem normal, como as regras gramaticais ou a capacidade de transformação de tais regras (regras sintagmáticas e transformacionais que compõem a gramática de qualquer língua segundo Chomsky). Por isso, pode servir unicamente para a comunicação associada a uma forma de comunicação autêntica que lhe empresta as regras. Além do mais, enquanto, na linguagem normal, os símbolos possuem uma peculiar independência do contexto, porque linguagem, vivência e ação se desenvolveram como sistemas autônomos entre si e, por isso, podem ser traduzidos um para o outro, os paleossímbolos possuem uma forte carga afetiva. Permanecem vinculados a determinadas situações, pois a ausência de uma gramática própria lhes impede dispor de autonomia com relação a outras formas comunicativas. Isso provoca a sua aderência, não somente à linguagem regida gramaticalmente, mas também às manifestações corporais e ações, o que gera a sua dependência dos contextos concretos e explica igualmente o seu caráter repetitivo e compulsivo. Sempre que o falante vivencia uma circunstância comunicativa que funciona como detonadora do paleossímbolo originado em cenas antigas, ele se faz presente na comunicação atual, provocando o sintoma.

A ausência de gramaticalidade dos paleossímbolos torna impossível a pura e simples comunicação paleossimbólica. Precisamente, a intromissão de elementos paleossimbólicos na comunicação normal ou a regressão da comunicação ordinária até o nível dos paleossímbolos origina a comunicação sistematicamente distorcida, explicando, também, porque somente se pode chegar aos paleossímbolos indiretamente, mediante a própria comunicação sistematicamente distorcida ou por meio dos sonhos, conforme revelaram os estudos de Freud. Nos sonhos, por exemplo, a vigilância dos mecanismos conscientes diminui consideravelmente, o que permite que os paleossímbolos se mostrem, mas, inclusive nesse caso, eles aparecem mesclados com elementos da comunicação normal, exigindo do psicanalista a tarefa de decifrar e classificar as distintas fases da comunicação. 
Essa característica "parasitária" dos paleossímbolos explica, ainda, porque eles podem originar uma linguagem privada que de outro modo seria impossível. Acontece que os paleossímbolos não dispõem de uma constância de significados, e a proporção de significados privados é considerável, o que implica que é muito difícil para os usuários dos paleossímbolos gerar uma identidade de significados aceita intersubjetivamente. A identidade de significados é uma propriedade indispensável da linguagem normal, mediante a qual os falantes sabem que suas expressões não podem mudar de sentido ao acaso, mas exige sempre um conjunto grande de significados duradouros que são compartidos intersubjetivamente. Por isso, o erro de um usuário que não compreende bem a gramática de um símbolo pode ser corrigido mediante as regras públicas que são seguidas efetivamente por todos. O uso de paleossímbolos desprovidos da identidade de significados aceito intersubjetivamente, seja porque os significados não são suficientemente duradouros, seja porque o uso privado dos símbolos a um nível excessivamente alto não permite uma compreensão mútua, torna impossível a comunicação. Isso parece pôr em risco, também, a própria explicação do funcionamento da linguagem privada como uma patologia, pois um dos fundamentos da linguagem privada é o mecanismo de "lembrança" privada dos símbolos: um usuário da linguagem privada tem que poder trazer sempre de volta o mesmo paleossímbolo em determinadas cenas que evoquem as enfermidades. Esse traço das patologias parece estar em contradição com a escassez de constância nos significados dos paleossímbolos. A explicação do mecanismo da linguagem privada exige que o enfermo sempre recorde privadamente o mesmo símbolo e, consequentemente, o seu significado privado; contudo, esses significados privados, quando estão relacionados aos peleossímbolos, mudam constantemente. Embora seja assim, a aparente contradição surge somente porque se ignora que a patologia não está no uso de paleossímbolos, mas na sua mescla com a linguagem ordinária. De fato, os paleossímbolos não possuem uma gramática profunda e regras transformacionais capazes de formar uma estrutura superficial. Os significados de seus símbolos são pouco constantes e privados, o que põe em risco a intersubjetividade de uma suposta comunicação 
nesse nível. A patologia não provém do uso dessa linguagem, mas de seu aparecimento repentino na linguagem gramaticalmente articulada, aderindo à estrutura formada por linguagem, vivência e ação. Ao se vincularem a um elemento linguístico normal, os paleossímbolos se relacionam profundamente com ele, o que confere uma carga fortemente afetiva ao processo. A vinculação traz privativamente à memória, sempre que está em jogo a cena à qual ele está associado, o que explica a "lembrança" privada dos significados. Esse caráter privado se deve ao fato de que, na organização pré-linguística dos símbolos, não se desenvolveram determinadas propriedades da comunicação propriamente linguística, como a separação entre emissor e destinatário, por um lado, entre signo, significado e referência, por outro, assim como entre os planos da realidade como ser e aparência ou mundo privado e público.

Outra característica da organização pré-linguística dos símbolos é o funcionamento insatisfatório do uso analítico da linguagem. Este permite, na linguagem normal, fazer a identificação de elementos e formar hierarquias de classes mediante a abstração de propriedades comuns. A identidade de propriedades que se pode obter pela abstração das particularidades de conteúdo é o fator que possibilita tanto a operação de identificação de símbolos como a inclusão de classes. No uso pré-linguístico de símbolos, a formação de classes não é totalmente suprimida, pois podem originar-se classes primitivas, mas é alterada. A estrutura fragmentária de classes de paleossímbolos não permite a reunião de elementos segundo critérios gerais; assim como uma estrutura amorfa dificulta a tarefa de identificar os elementos das classes. A identidade de propriedades abstratas é substituída pela união de objetos concretos por meio de critérios subjetivos que podem parecer convincentes. Quer dizer, a união de elementos sob propriedades identificáveis, obtidas por abstração de conteúdos concretos que formam as classes na comunicação analítica é substituída pela agregação de elementos segundo critérios que o sujeito determina em função de intencionalidades. Contudo, os paleossímbolos devem, de alguma maneira, ser usados em interações, seja com base em ações técnicas e analíticas ou comunicativas, o que exige que eles possuam protoformas de intersubjetividade. 
Isto se torna mais explícito em formas primárias de desenvolvimento tanto ontogenéticas, como filogenéticas. As imagens animistas do mundo são exemplos da presença de paleossímbolos capazes de organizar a intersubjetividade fortemente presentes na comunicação linguística. O mito não pode, naturalmente, ser uma situação pré-linguística pura, pois possui uma lógica própria, regulada gramaticalmente, enquanto a organização pré-linguística possui uma estrutura que não chega a configurar uma lógica e somente pode participar da comunicação associada à linguagem normal. Os paleossímbolos estão mais claramente presentes e integrados ao mito que à linguagem moderna, em que o seu aparecimento denuncia uma comunicação distorcida.

Embora a descrição da etapa geneticamente anterior do desenvolvimento da linguagem seja uma construção teórica porque não pode ser encontrada em nenhuma forma de comunicação em estado puro, não obstante o psicanalista deve pressupô-la como explicação da comunicação sistematicamente distorcida, pois as patologias da linguagem ocorrem por causa da mescla de elementos das distintas etapas entre si. Podem-se perceber duas formas de presença de paleossímbolos na comunicação ordinária: ou os símbolos da linguagem pública são expulsos para o nível dos paleossímbolos ou, ao contrário, os paleossímbolos irrompem na linguagem normal (HABERMAS, 1985, p. 354).

A enfermidade pode ser compreendida mediante o mecanismo de repressão. Inicialmente, os símbolos da linguagem pública compartilhados intersubjetivamente são empurrados para o nível dos paleossímbolos. Em determinadas situações traumáticas vividas na infância, pode acontecer que as forças do consciente ajam de modo a ocultar de si mesmas tanto essas cenas como as pessoas primárias de referência. Os símbolos problemáticos são "dessimbolizados", pois perdem seu caráter público e intersubjetivo e, para evitar qualquer lacuna na comunicação, é inserido em seu lugar um símbolo insuspeito, que não pode denunciar o trauma nem para outros, nem para si mesmo. Forma-se, assim, o sintoma que o enfermo repetirá compulsivamente em todas as ocasiões cujas circunstâncias despertem a presença do símbolo reprimido. A tarefa da Psicanálise consiste em ajudar o enfermo a recordar o mecanismo originário da repressão, embora trazer à mente os símbolos 
"dessimbolizados" depende da capacidade do enfermo para superar gradualmente as barreiras interpostas pela consciência, o que não pode ser feito isoladamente pelo enfermo. Exige o diálogo psicanalítico. Esse processo permite a "ressimbolizacão" dos símbolos excomungados da comunicação pública, inicialmente alojados entre os paleossímbolos no grau da comunicação pré-linguística; isto explica o comportamento patológico, pois os paleossímbolos não servem para a comunicação propriamente dita. Os paleossímbolos dispõem de uma forte carga emocional e estão profundamente vinculados ao contexto, o que permite que sejam sempre "recordados" em situações que ameaçam o enfermo. Ao mesmo tempo, graças ao seu caráter privado e da escassez de constância nos significados, torna difícil a comunicação ordinária baseada na intersubjetividade dos significados.

Esse mecanismo de repressão, além de ser dirigido pelo próprio sujeito, que foge de uma situação insustentável para ele, contra si mesmo, gera outro fenômeno patológico que se volta contra a realidade externa que se tornou insuportável. O sujeito, vinculado a uma realidade ameaçadora, pode introduzir mecanismos de defesa complementares à "dessimbolização", como são a projeção e a negação: na "dessimbolização”, parte da comunicação linguística é excomungada, sendo remetida ao nível privativo dos paleossímbolos, pois o sujeito deve proteger a sua consciência das "lembranças" de cenas originais; na projeção e negação, o alvo não são as "lembranças" subjetivas, mas uma realidade da qual o enfermo tenta fugir. Por isso, em lugar de remeter os símbolos da linguagem pública à etapa dos paleossímbolos, traz os paleossímbolos para a linguagem pública. Mesclada com corpos estranhos que não dispõem da gramaticalidade da comunicação normal, o comportamento patológico é igualmente incompreensível, pois o enfermo não pode suportar a realidade na qual vive e a nega e, em seu lugar, projeta uma outra realidade cheia de elementos paleossimbólicos. Naturalmente, essa forma de comunicação híbrida carece das mesmas regras lógicas do caso anterior, uma vez que os paleossímbolos não distinguem explicitamente entre ser e aparência, mundo público e privado, etc. Além disso, a realidade projetada que substitui a realidade negada é carregada emocionalmente e é defendida pelo enfermo, que resiste fortemente 
a qualquer tentativa de expulsão dos paleossímbolos, seja na práxis vital, seja na clínica. Na vida cotidiana, o enfermo apresenta sintomas, como são a compulsão ou repetição de comportamento e a desarticulação entre os planos da linguagem, vivência e ação, sem percebê-los. Contudo, os paleossímbolos que estão sempre presentes na linguagem normal podem contribuir para a criatividade tanto nos casos normais, como nos patológicos, podendo inclusive ser usados como auxiliares do tratamento.

Os pressupostos teóricos que descrevem a linguagem normal e as duas etapas geneticamente diferenciadas da comunicação demonstram a insuficiência da compreensão hermenêutica, pois eles se baseiam em determinados problemas de comunicação que não podem ser resolvidos, apelando para a habilidade dos participantes, adquirida por tradição. As patologias da linguagem se caracterizam pela resistência ao tratamento e uma simples habilidade adestrada não é suficiente para superá-las e levar o enfermo à autorreflexão. Isso exige uma teoria da comunicação sistematicamente distorcida que, no caso das enfermidades mentais, é a Psicanálise; para as sociedades, é a teoria da ação comunicativa.

Foi justamente a experiência da resistência do enfermo mental que permitiu a Freud desenvolver um modelo estrutural que explica a comunicação sistematicamente distorcida e desenvolver uma teoria necessária para o trabalho analítico de dissolução das enfermidades, ultrapassando os limites da reflexão hermenêutica. Durante o tratamento, Freud percebeu que o paciente põe em jogo processos de defesa que se tornam mais fortes quanto mais o analista se aproxima das supostas causas dos sintomas. Por esta razão, ele percebeu a existência de uma dupla estrutura no sujeito; por um lado, os mecanismos responsáveis pela repressão, reunidos no "ego"; por outro, o conjunto de elementos reprimidos, representados pelos paleossímbolos, o "id". Enquanto o "ego" permanece vinculado à comunicação pública, o "id" não pode ser conhecido diretamente, mas por meio da análise dos sonhos ou pelas patologias da linguagem (a repressão de símbolos no plano do inconsciente ou a irrupção do inconsciente na comunicação pública). Freud observou, também, que os mecanismos de repressão do "ego" quase nunca são conscientes, mas, se o "ego" opera com processos 
inconscientes, é porque algum outro fator age sobre ele, determinando suas atividades. Freud introduziu, então, um terceiro elemento no modelo estrutural, o "superego", que representa as expectativas do papel que as pessoas de referência esperam do indivíduo e pode obrigar o seu "ego" a agir contra os impulsos do "id", inclusive sem um conhecimento explícito de tais mecanismos de defesa.

A estrutura da personalidade de Freud é uma teoria que explica como se formam os comportamentos desviados com relação à comunicação normal. Demonstra que a solução das comunicações sistematicamente distorcidas depende do diálogo psicanalítico, o qual é executado nas condições especiais da clínica, as quais não reproduzem as situações de fala cotidianas baseadas na tradição. Prova, além disso, que a reflexão apoiada na competência natural dos falantes compartilhada intersubjetivamente não pode nem explicar o comportamento desviado, nem corrigi-lo. A Psicanálise de Freud, contudo, não conseguiu desenvolver plenamente a metodologia autorreflexiva que a sua própria teoria projetou por causa das concessões feitas ao cientificismo, à fisiologia, por exemplo. Somente uma teoria crítica que reflete sobre seus próprios pressupostos é verdadeiramente capaz de recusar as falsas objetivações. Não obstante, Habermas acredita que essa tarefa não estava ainda realizada e considera que os estudos sobre a comunicação sistematicamente distorcida apenas revelavam a necessidade de uma teoria da ação comunicativa que ele apresentará nos anos posteriores.

\section{Referências}

APEL, K.-O. (Org.). Sprachpragmatik und philosophie. Frankfurt am Main: Suhrkamp Verlag, 1982.

BOHMAN, J. Formal pragmatics and social criticism: the philosophy of language and the critique of Ideology in Habermas's theory of communicative action. Philosophy and Social Criticism, n. 11, p. 331-353, 1986.

BOHMAN, J. Communication, ideology and democratic theory. American Political Science Review, v. 84, n. 1, p. 93-109, 1990. 
COLBURN, K. Critical theory and the hermeneutical circle. Sociological Inquiry, n. 56, p. 367-380, 1986.

DEETZ, S. Systematically distorted communication and discursive closure. In: CRAIG, T.; MULLER, H. Theorizing communication: readings across traditions. California: Sage, 2007. p. 457-472.

FERRY, J.-M. L'Éthique da communication. Paris: Presses Univ. France, 1987.

GADAMER, H.-G. Hermeneutik II wahrheit und methode. Tübingen: Mohr, 1993. (Gesammelte Werke, 2)

HABERMAS, J. On systematically distorted communication. Inquiry, n. 13, p. 205-218, 1970.

HABERMAS, J. Zur logik der sozialwissenschaften. Frankfurt am Main: Suhrkamp Verlag, 1985.

HABERMAS, J. Erkenntnis und interesse. 11. Aufl. Frankfurt am Main: Suhrkamp Verlag, 1994.

HABERMAS, J. Theorie des kommunikativem Handelns. Frankfurt am Main: Suhrkamp Verlag, 1995a. 2 v.

HABERMAS, J. Vorstudiem und ergänzungem zur theorie des kommunikativem Handelns. Frankfurt am Main: Suhrkamp Verlag, 1995b.

HORENGARTEN, W. M. Language games versus communicative action: Wittgenstein and Habermas on language and reason. Ann Arbor, Michigan: Univ. Microfilms International, 1991.

HUSPEK, M. Taking aim on Habermas's critical theory: on the road toward a critical hermeneutics. Communication Monographs, v. 58, n. 2, p. 225-233, 1991.

LAFONT, C. La razón como lenguaje. Madrid: Visor, 1993.

LOPARIC, Z. Um olhar epistemológico sobre o inconsciente freudiano. In: KNOBLOCH, F. (Org.). O inconsciente: várias leituras. São Paulo: Escuta, 1991. p. 45-58. 
McGEE, B. Emancipatory rhetoric in a instrumental milieu: Habermas and the academic debate. In: ROGERS, J. Transforming debate. New York: The International Debate of Education Association, 2002. p. 10-26.

MENDELSON, J. The Habemas-Gadamer debate. New German Critique, n. 18, p. $44-73,1979$.

MISGELD, D. Discourse and conversation: the theory of communicative competence and hermeneutics in the light of the debate between Habermas and Gadamer. Philosophy \& Social Criticism, n. 4, p. 321-344, 1977.

MOOTZ, F. J. III. The ontological basis of legal hermeneutics: a proposed model of inquiry based on the work of Gadamer, Habermas, and Ricoeur. Boston University Law Review, n. 68, p. 523-617, 1988.

NEGRU, T. Gadamer - Habermas Debate and Universality of Hermeneutics. International Journal of Philosophy of Culture and Axiology, n. 2, p. 113-119, 2007.

PEREZ, D. O. (Org.). A eficácia da cura em Psicanálise: Freud - Winnicott Lacan. Curitiba: CRV, 2009.

PRADO Jr., B. Filosofia da Psicanálise. São Paulo: Brasiliense, 1991.

SAFATLE, V. Autorreflexão ou repetição: Bento Prado Jr. e a crítica ao recurso frankfurtiano à Psicanálise. Ágora: Estudos em Teoria Psicanalítica, Rio de Janeiro, v. 7, n. 2, p. 279-292, 2004.

RICOEUR, P. Ethics and culture: Habermas and Gadamer in Dialogue. Philosophy Today, n. 17, p. 153-165, 1973.

SHAPIRO, S. Rhetoric as ideology critique: the Gadamer - Habermas debate reinvented. Journal of the American Academy of Religion, v. 62, n. 1, p. 123-150, 1994.

STEIN, E. Dialética e hermenêutica. In: VALLS, A. (Org.). Jürgen Habermas dialética e hermenêutica: para uma crítica da hermenêutica de Gadamer. 4. ed. Porto Alegre: L\&PM, 1987. v. 1, p. 98-136. 
STEIN, E. Aproximações sobre a hermenêutica. 2. ed. Porto Alegre: EDIPUCRS, 2004.

VALLS, Á. (Org.). Jürgen Habermas dialética e hermenêutica: para uma crítica da hermenêutica de Gadamer. 4. ed. Porto Alegre: L\&PM, 1987.

WITTGENSTEIN, L. WERKAUSGABE. 5. Aufl. Frankfurt am Main: Suhrkamp Verlag, $1989.8 \mathrm{v}$.

Recebido: 14/09/2011

Received: 09/14/2011

Aprovado: 28/01/2012

Approved: 01/28/2012 